\title{
Palavras em movimento: um modo de dizer e de significar
}

\author{
Words in movement: a way of saying and meaning \\ Ana Luiza Artiaga R. da Motta ${ }^{1}$ \\ Universidade do Estado de Mato Grosso
}

\begin{abstract}
- RESUMO: No texto a letra toma corpo e dá visibilidade as palavras de nossa homenagem a ilustre professora Eni Orlandi. É-nos caro pontuar, nesta escrita, pelos estudos da linguagem, o quão nos beneficiou os trabalhos teóricos e a amizade honrosa da professora Eni Orlandi. A força de seus trabalhos teóricos com a Análise de Discurso tem nos permitido, pelas reflexões, questionar o sujeito, a língua e a história. De modo que optamos, assim, por dividir este artigo em duas partes. A primeira por dizer sobre a autora em relação a sua produção, ao que selecionamos um breve recorte de sua vasta produtividade acadêmica de pesquisa. Em segundo momento, falaremos de sua presença, notoriedade profissional na Universidade do Estado de Mato Grosso.
\end{abstract}

- PALAVRAS-CHAVE: Discurso, sujeito, homenagem, produtividade

- ABSTRACT: In the text the letter takes body and gives visibility to the words of our tribute to the illustrious professor Eni Orlandi. It is expensive for us to point out, in this writing, by the studies of language, how much the theoretical works and the honorable friendship of Professor Eni Orlandi have benefited us. The strength of her theoretical work with Discourse Analysis has allowed us, through reflections, to question the subject, language and history. So that we have chosen to split this article into two parts. The first part is to tell about the author in relation to her production, to which we selected a brief cut of her vast academic research productivity. Secondly, we will talk about her presence, professional notoriety at the State University of Mato Grosso.

- KEYWORDS: Discourse, subject, tribute, productivity

O pé na terra

A paz na Terra, amor

O sal da Terra!

Beto Guedes

\section{Tecer: um modo de dizer}

Este texto emerge de uma condição de produção distinta, o de homenagem a Professora Eni Orlandi. De forma que esta escrita não tem a pretensão de fazer uma análise de uma materialidade discursiva, mas o de se dizer em dois movimentos. $\mathrm{O}$ primeiro, se assim, couber, em palavras, dizer sobre a significação teórica da pesquisadora. Em segundo momento, o afeto, o sal da terra, que nos é caro dizer e

\footnotetext{
${ }^{1}$ Doutora em Linguística pela UNICAMP. Professora do Departamento de Letras e do Programa de Pós-Graduação em Linguística da Universidade do Estado de Mato Grosso/UNEMAT. Texto apresentado no "V ENCONTRO EM ANÁLISE DO DISCURSO: ESTUDOS ORLANDIANOS", de homenagem a Professora Dra. Eni Orlandi, na Universidade Estadual de Mato Grosso do Sul/UEMS em parceria com a UNEMAT. analuizart@unemat.br
} 
significar, pela escrita, em face às interlocuções pessoais, as acadêmicas e as institucionais com a Universidade do Estado de Mato Grosso.

Deste modo, este texto não tem o caráter de uma pesquisa. Porém, se coloca pela vivacidade das relações políticas que conforme Rancière (1995) o político se significa na linguagem. E como dizer sobre o saber, linguagem, senão pela língua e discurso? Com M. Pêcheux, na França, a corporeidade, visibilidade teórica do estudo do discurso. Conforme P. Henry (1997), o percurso teórico da Análise de Discurso se institui em meio a rompimentos, movimentos ao estruturalismo e críticas ao formalismo. P. Henry (op.cit.) ao dizer sobre Pêcheux, em relação ao momento em que se discute a linguagem, diz que "Definir um novo instrumento científico é para ele o melhor meio de evitar a rotina da crítica filosófica tradicional". (p.19). Depreende-se que "[...] só, há instrumento em relação a uma teoria. Por aí se estabelece o projeto de Michel Pêcheux nestes fins dos anos 60.” (MALDIDIER, 2003, p.20).

A teoria da Análise de Discurso proposta por M. Pêcheux se institui entremeio a distintas áreas do conhecimento e a estas atribuindo questões. A Linguística, pela não transparência da linguagem, do Materialismo Histórico, de que há um real da história e de que a história que se produz, não é transparente e da Psicanálise, a contribuição com o deslocamento necessário da noção de homem para a de sujeito. A teoria da Análise de Discurso se constitui entremeio a essas regiões de ciência, de conhecimento. (ORLANDI, 1999).

Da Análise de Discurso do francês Michel Pêcheux, Orlandi constrói, no Brasil, pelas pesquisas, a produção do conhecimento teórico do estudo do discurso. $\mathrm{O}$ investimento das/nas pesquisas, produtividades bibliográficas são de notórios conhecimentos e que se tornam referências teóricas nos estudos da linguagem. Isto não se dá ao apagar das luzes. Há investimentos, produtividade, sociabilidade acadêmica. Com Orlandi, no Brasil, a Análise de Discurso avança. Um novo tempo, diremos, tem início e evoca pesquisa e deslocamentos para os estudos da linguagem. Como disciplina, tem seu curso, percurso no processo de institucionalização acadêmica. Há trabalho.

No Brasil, na cidade do Rio de Janeiro, conforme Orlandi (2003) ${ }^{2}$, o Congresso de Ciências Políticas lhe possibilita conhecer/dizer a Michel Pêcheux sobre seus trabalhos com os estudos do discurso, no Brasil. Segundo Orlandi a conversa, em um dos bares, se efetiva em meio ao cheiro de pastéis e caldo de cana. Bem Brasil! De forma que o Rio de Janeiro os viu e ouviu. Discursos. Acontecimentos de linguagem.

É importante dizer, da condição de produção do discurso que se estabelece a partir de Orlandi, do seu lugar de pesquisadora para aquele que a autora toma como referência de seus estudos - M. Pêcheux. Orlandi - do seu lugar de pesquisadora, a presença, os escritos são marcas da trajetória, de pesquisa, que se dá a ler. É da produtividade científica bibliográfica, que Eni Orlandi verticaliza e expande a produção da teoria da Análise de Discurso, para outras línguas, mundos, que internacionalizam o seu nome e o do seu país de origem - o Brasil.

Orlandi pela vivência da pesquisa se delineia pela linguagem, os gestos de interpretação, entendendo que "Ao se passar da instância da organização para a da ordem, se passa da oposição empírico/abstrato para a instância da forma material em que o sentido não é conteúdo, a história não é contexto e o sujeito não é origem de si." (ORLANDI, 1996, p.49). Do percurso - A teoria da Análise de Discurso permite-se que se depreenda que o discurso é o espaço de constituição e de relações de sentidos.

\footnotetext{
${ }^{2}$ Ler sobre in. A Inquietação do Discurso (Re) ler Michel Pêcheux Hoje.
} 
Dizer sobre Orlandi, como pesquisadora, nos é caro. Pelos seus trabalhos com a linguagem possibilita-nos que avancemos e que se depreenda que o sentido não existe como se fosse à flor da pele, a película da palavra. Há, o efeito ideológico elementar, aquele que naturaliza o olhar a opacidade das palavras e faz com que o sujeito leitor pense que o sentido esteja alocado a literalidade. De forma que não se questiona as condições de produção, na linguagem, o modo como a história intervém no processo constitutivo de produção do conhecimento.

Dessa forma, Orlandi com seus trabalhos, a partir de M. Pêcheux, faz saber que pelo discurso se produz efeitos de sentido e que a linguagem tem seu funcionamento, plasticidade. Há uma engrenagem histórica, política e ideológica, no discurso. Como diz Pêcheux (1975) de que "não há discurso sem sujeito e nem sujeito sem ideologia". Esse efeito faz compreender que "[...] o sujeito se constitui e se significa por ser afetado ("o indivíduo é interpelado em sujeito pela ideologia") pela língua e pelo mundo (relação do simbólico e da história: "a discursividade é a inscrição dos efeitos da língua, sujeita a falha, na história”). (ORLANDI, 2001, p.46). É assim, necessariamente, que a língua funciona e faz sentido. A língua tem a sua opacidade e a ideologia produz o efeito de naturalização dos sentidos.

Com efeito, a ideologia naturaliza a relação do sujeito com a linguagem e deste efeito apaga-se a posição sujeito como crítico, aquele capaz de produzir uma incisão pelo discurso e desconstruir o sentido linear. Orlandi (1999) enfatiza que pelo entrecruzamento dos dispositivos teóricos e analíticos que se compreende o processo discursivo.

Do ponto de vista teórico da Análise de Discurso tem-se a compreensão de que a análise é construída em um processo de significação, e, que, há um batimento produtivo, no gesto do analista, compreender o movimento da linguagem que entrecruza a descrição e a interpretação. "A língua se apresenta, assim, como a base comum de processos discursivos". (PÊCHEUX, 1995, p.91). Esse movimento profícuo, o de compreender as engrenagens da linguagem, faz entender que há uma base e que é sobre esta que os processos se efetivam, desenvolvem.

A linguagem é parte do mundo, já está lá, aqui, em circulação. O sujeito por sua vez tem a ilusão o de ser início, a origem (ORLANDI, 1999). Esse modo de dizer da autora coloca em questão a relação sujeito e mundo e traz à tona o quanto o sujeito é, necessariamente, interpelado a dar sentido a construir sentidos. Segundo Orlandi (op.cit.) as palavras constroem sentidos por que têm a sua significação. Há uma memória discursiva que as sustentam. De modo que é distintivo o sentido de uma palavra. Por exemplo, terra. A palavra não tem o sentido em si mesma. Tem sentidos diferentes, pois diferentes são as posições ideológicas, em que se inscreve aquele que a produz. (PÊCHEUX, 1995). As palavras estão em movimento percurso e não tem a origem no sujeito. E nem o sentido a literalidade da palavra, mas é preciso que se considere o processo de constituição do sentido das formações discursivas em que se produz a linguagem.

Orlandi (2004) nos faz pensar que as relações em sociedade são relações de sentidos. E diz "Na análise a que me filio, o dispositivo alia a questões de deriva (deslizamento, efeito metafórico) à própria ordem da língua. Entretanto, como diz M. Pêcheux (1991), não se trata de pensar só o outro linguageiro, mas o outro nas sociedades e na história". (p.24). Ou seja, vivemos em sociedade e é pela referência à sociedade e a história que as questões se abrem a interpretação. No tempo e no espaço pela própria existência, essência de/e como sujeito em sociedade consumimos palavras, sons, imagens. Discurso. Interpretação. 
Orlandi, no livro Princípios e Procedimentos (1999) postula a importância de se compreender a significância da linguagem, a interlocução do sujeito com o mundo. Diremos que - no tempo e no espaço - a linguagem é vida. Da relação do homem com o mundo sempre há traços, desenhos, imagens, linguagens que mediam a relação entre este e ou aquele. A interlocução, sociabilidade é parte, invenção do cotidiano, da relação do sujeito com o mundo.

De Orlandi dentre os valiosos trabalhos desenvolvidos tocamos, ainda que breve, o interesse da autora pelo discurso/cidade. O modo como a autora toma a cidade, pelo sentido, pelo simbólico e faz intervir as condições de produção na/pela linguagem. Diz que "a cidade tem assim seu corpo significativo. E tem nele suas formas." (ORLANDI, 2004, p31). A cidade diz por uma confluência de linguagens, imagens, narratividades, escritas, desenhos, neons, sons, que evocam sentidos. Instigam pesquisas, questões. Como diz Aumont (1993) há um olho que vê. O olho e o tempo. Diz que "Nossos olhos estão em constante movimento, o que faz variar a informação recebida pelo cérebro". (p.31). São muitas informações, intervenções, tecidas pelo/no tecido da cidade. Profusão de sons, cheiros e sabores. Corpos. A cidade e o movimento. A atratividade da leitura atenta do ouvido, do olfato e do paladar. O sentido aflora. A cidade e sua partitura.

Orlandi, no livro Cidade dos Sentidos (2004), produz uma tessitura teórica densa e de uma grandeza que faz com que a leitura se desloque do que se lineariza na própria forma material. Na divisão da cidade como tabuleiro de xadrez. (RAMA,1985). Orlandi traz a cidade, a sua corporeidade, eloquência para o campo teórico da Análise de Discurso e produz uma leitura inquietante de divisão da cidade, do que fica às margens da cidade e que pelo discurso do capitalismo, tornam-se opacos, ásperos, espaço de segregação. Desse ponto de vista, o modo como a autora toma a cidade nos toca como pesquisadora e nos permite pensar pelo funcionamento da linguagem a determinação ideológica e política no tecido urbano, pelo discurso. (MOTTA, 2012).

De forma que os escritos de Orlandi (op.cit.) sobre a cidade nos faz pensar as relações de sentidos entre sujeito e sociedade entendendo que estes são povoados pelas multiplicidades de discursos que migram pelas relações econômicas, políticas e sociais. E é assim, que em meus trabalhos sobre a orientação de Orlandi construí a tessitura da pesquisa no Mestrado e no Doutorado.

\section{Na UNEMAT: o afeto e a inscrição teórica}

A Universidade do Estado de Mato Grosso - UNEMAT está geograficamente localizada na cidade de Cáceres, considerada o portal do Pantanal de Mato Grosso. Assim, como tantas IES, a UNEMAT tem em seu percurso sócio histórico e político o de ultrapassar as fronteiras territoriais pelas relações institucionais, dentre estas, sente-se honrada pelas interlocuções acadêmicas, de excelência, com a Universidade Estadual de Campinas, UNICAMP, com a Professora Eni Orlandi, Eduardo Guimarães, Mónica Zoppi-Fontana e demais pesquisadores. $\mathrm{O}$ afeto, a proximidade acadêmica e a inscrição teórica desencadearam em trabalhos, de MINTER e DINTER no processo de qualificação de profissionais da área da linguagem da UNEMAT.

É importante, que se registre e dê visibilidade à parceria entre a UNEMAT e a UNICAMP, a ambiência constitutiva da pesquisa e o ensino, os diálogos estabelecidos com a Professora Eni Orlandi e o percurso que se consolida na produção do conhecimento na UNEMAT. O marco significativo se desencadeia pelo processo de qualificação profissional em 1994, o Curso de Espacialização para os docentes e, posteriormente, em 1997, o Minter como um modo de qualificar um quadro 
significativo de professores, dentre estes professores da rede pública de ensino, egressos da UNEMAT. Em 1999, outro acontecimento importante se efetiva com a aprovação do PROCAD/Amazônia o que se delineia com o ingresso de professores no Doutorado em Linguística na UNICAMP. Em 2009 o Dinter. Percursos. Relações políticas e institucionais que categoricamente, pela qualificação, desloca o modo de se compreender os estudos da linguagem nos cursos de licenciatura. O modo distintivo, da produtividade na instituição, se dá pela forma com que as pesquisas são construídas e avançadas fazendo compreender a linguagem, a ideologia, o sujeito e a história.

A Universidade do Estado de Mato Grosso lhes agradece pelo modo profícuo com que nos ensinastes pelo movimento da pesquisa, do fazer ciência a atribuir questões. Como bem salienta Paul Henry (1997), a ciência vem para colocar questões. Nessa ambiência, a pesquisa tomou corporeidade visibilidade pelas publicações e que culmina na instituição do Centro de Estudos e Pesquisas em Linguagem - o CEPEL. Esse modo de pensar a Universidade e sua produtividade para a sociedade culminou na escrita e aprovação do projeto e de institucionalização do Programa de Pós-Graduação de Mestrado em Linguística/PPGL em 2009 e em 2015, com a aprovação da proposta de Doutorado em Linguística na UNEMAT pela CAPES.

Nesta escrita se faz necessário retomarmos o percurso de institucionalização do PPGL em que estiveram juntos com a UNEMAT, a Professora Eni Orlandi, Eduardo Guimarães, Mónica Zoppi-Fontana entre outros direcionando, embrenhando nas terras de Mato Grosso fazendo ciência. A pesquisa, a política institucional de qualificação profissional e a sua produtividade dignifica a instituição com seu status de universidade pelos Programas, dente estes a área da Linguística.

Trata-se de modos de institucionalização científica de estudos da linguagem na UNEMAT e que implicam em desestruturas que se reestruturam no tempo pela própria sutileza que a leitura e a pesquisa oferecem. São percursos, deslocamentos, produtos de um processo de qualificação provenientes das relações políticas e institucionais entre a Universidade do Estado de Mato Grosso/UNEMAT e a Universidade Estadual de Campinas/Unicamp.

Para tanto, neste acontecimento de linguagem, de homenagem a Professora Eni Orlandi, pensamos ser salutar registrar que a feitura de seus trabalhos, de seus escritos, pelo o modo de questionar a tessitura do discurso e de dizer sobre a linguagem em inúmeros artigos, livros, eventos, seminários, encontros na área da linguagem corroboram para a formação do cidadão brasileiro. Na posição de professor, neste país, em curso de graduação em licenciatura e de pós-graduação, as interlocuções com a escola da rede pública de ensino a partir dos estudos do francês M. Pêcheux e Eni Orlandi no Brasil nos permite alargar os conhecimentos e interrogar a linguagem pelos gestos de interpretação.

Por fim, ressaltamos, sobretudo, os escritos de Orlandi (1990) em Terra à Vista, a grandeza nas/pelas engrenagens das palavras. O modo como desnuda-se o olhar do leitor para a linguagem ritualizada no que tange a descoberta do Brasil. Lá se tem, diremos, pelo discurso, o Brasil à vista, o país capitaneado pelo olhar europeu e seus gestos, modos de domesticação que tecem sentidos sobre a historicização do ensino, no Brasil.

Pela teoria da Análise de Discurso produzida por Orlandi, no Brasil, é possível, pelos escritos, depreender os gestos de interpretação sobre o modo de dizer da autora, que, pela arte das letras dá corpo à palavra. Palavras que como diz Orlandi (1990), no livro As Formas do Silêncio que "antes de ser palavras foram silêncio". Diz Manoel de Barros no texto - O apanhador de desperdicios - "uso a palavra para compor meus 
silêncios"3. E, eu, neste acontecimento tomo a palavra e construo este texto de homenagem que, simbolicamente, congrega muitos discursos do que se constuiu constituiu na/com a Universidade do Estado de Mato Grosso. O agradecimento a Eni Orlandi pelo percurso, generosidade! Engenhosidade de excelência com a linguagem o modo como se diz da leitura, da interpretação pela teoria da Análise de Discurso. Discurso que se compreende como estrutura e acontecimento aberto a significação.

Assim, o ponto de parada, no final da escrita e, aqui, compreende-se que não coube dizer em palavras porque há a incompletude e a palavra desliza goteja, não para. Silêncio.

Obrigada, pelo constructo teórico, orientação de excelência e, sobretudo, a amizade, a minha gratidão...

\section{REFERÊNCIAS}

AUMONT, Jacques. A Imagem. Trad. Estela dos Santos Abreu e Claudio C. Santoro Campinas, SP: Papirus, 1993, (coleção Ofício de Arte e Forma)

HENRY, Paul. Os fundamentos teóricos da Análise Automática do Discurso de Michel Pêcheux (1969). In: GADET, F.; HACK, T. Por uma análise automática do discurso: uma introdução à obra de Michel Pêcheux. Tradução: B. Mariani et al. Campinas, São Paulo: Editora da Unicamp, 1997.

MALDIDIER, Denise. A inquietação do discurso - (Re) ler Michel Pêcheux Hoje. Tradução; Eni P. Orlandi, Campinas, Pontes, 2003.

MOTTA, Ana Luíza Artiaga R. A regularidade jurídica e o desvão urbano. In: Estudos da linguagem: língua, sujeito e história. (org.) ZATTAR, Neuza, DI RENZO, Ana Maria. Campinas: Pontes Editores, 2012.

ORLANDI, Eni, P. Terra à vista - Discurso do confronto: Velho e Novo Mundo. Campinas, SP: Editora da UNICAMP, 1990.

da Unicamp, 1997.

As formas do silêncio: no movimento dos sentidos. 5 ed. Campinas-SP: Ed. 2001 .

Discurso e Texto: formação e circulação dos sentidos. Campinas, SP: Pontes,

Cidade dos Sentidos. Campinas, SP: Pontes, 2004.

2007.

Análise de discurso: princípios e procedimentos. 7. ed. Campinas, SP: Pontes,

PÊCHEUX, Michel. Semântica e discurso: uma crítica à afirmação do óbvio. Trad. Eni P. Orlandi. 2. ed. Campinas, UNICAMP, 1995.

RAMA, Angel. A cidade das Letras. Tradução Mario Vargas Llosa, Et.al- São Paulo: Brasiliense, 1985.

RANCIÈRE, Jacques. Políticas da escrita. Trad. Raquel Ramalhete [et al]. Rio de Janeiro: Ed. 34, 1995. 265 p. (Coleção Trans).

\footnotetext{
${ }^{3}$ Ver - Manoel de Barros - Texto: $\mathbf{O}$ apanhador de desperdícios em http://www.asomadetodosafetos.com/ acesso em maio/2017.
} 
Recebido em: setembro de 2017.

Aprovado em: novembro de 2017.

\section{Como citar este trabalho:}

MOTTA, A. L. A. R. da. Palavras em movimento: um modo de dizer e de significar. Traços de linguagem, v. 2, n. 1, p. 76-82, 2018. 